\title{
Pathological Studies and Pathological Principles on the Management of Extension Injuries of the Cervical Spine
}

\author{
H. Kinoshita, MD, ${ }^{1}$ H. Hirakawa, $\mathrm{MD}^{2}$ \\ ${ }^{1}$ Director, Hiroshima Rehabilitation Workshop, Hiroshima, fapan, ${ }^{2}$ Director, \\ Higashi Nagano National Hospital, Nagano, Japan.
}

\begin{abstract}
Summary
Extension injury to the arthritic spine of elderly individuals involves rupture of the anterior longitudinal ligaments and disks at several levels, but no bony injury can be observed on $X$-ray. There are many small focal haemorrhages in the central portion of the spinal cord and the injury is often accompanied by incomplete paresis. As the injury is a stable injury with the posterior ligament complex being intact, it is only necessary to immobilise the cervical spine conservatively. Laminectomy is not indicated.

In hyperextension injury of the rigid cervical spine and in momentary posterior dislocation observed in middle aged individuals, rupture of the anterior longitudinal ligament and disk is observed at a single site, but being spontaneously reduced, traumatic findings cannot be observed on $X$-ray. The spinal cord is crushed at the site of injury to bring about severe neural damage. When this type of injury is diagnosed or suspected, further damage may be inflicted on the spinal cord if skull traction is made with calipers in the extended position and the condition at the time of injury is reproduced. Therefore, the patient should be nursed in a shell or between sandbags in a neutral position or even in a position of slight flexion. In extension fracture dislocation with compression which resembles on $X$-ray a flexion injury, all of the three columns of the spine are destroyed to bring about an extremely unstable condition. As the spinal cord is extensively injured to involve several segments, decompression surgery for relief of neuroparalysis should not be performed when complete paralysis develops simultaneously with fracture dislocation. Therefore, it should be first treated conservatively with skull traction, and in cases where stability cannot be restored, surgical fixation of the spine should be performed.
\end{abstract}

Key words: Pathology; Management; Extension cervical spines injury; Cervical spinal cord.

There are many different types of extension injuries of the cervical spine and spinal cord. 
Barnes (1948) recognised 2 types of hyperextension injury of the cervical spine: (1) posterior dislocation (under 50 years of age) and (2) injury to arthritic spine (all more than 50 years of age). Taylor and Blackwood (1948) described a case of hyperextension dislocation which underwent spontaneous reduction and presented no dislocation on X-ray. Forsyth (1964) described extension injuries of the cervical spine which presented forward displacement and therefore masqueraded the flexion injuries.

Guttmann (1966) detailed 4 cases of hyperextension injuries of the cervical spine in patients with ankylosing spondylitis. Burke (1971) summarised 5 types of extension injuries of the cervical spine and detailed the pathological studies related to clinical symptoms.

As the authors observed these different types of extension injuries to the cervical spine on autopsy, they will describe the pathological findings of these cases and discuss how to manage these cases based on post-mortem studies.

\section{Materials}

During the past 30 years the authors conducted post-mortem examination on 26 cases of cervical spinal cord injury at the Chugoku Rosai Hospital. Of these cases described in this report, 9 had a hyperextension injury of the cervical spine.

\section{Results}

\section{Extension injuries to arthritic spine}

Cases 1, 2, 3 and 4 are all elderly individuals who sustained extension injuries to the arthritic spine (Table). Two of the patients had trauma to the face and forehead. Paresis was observed in 3 patients $(75 \%)$ and bone injury was absent on X-ray in 3 patients. Only in case 4, a small crack fracture of osteophyte was seen in anterior inferior margin of the vertebra. All had rupture of anterior longitudinal ligament and disc. The characteristic pathological feature of extension injuries of the aged is the multiplicity of the injury, particularly as it involves more than 1 level and can be seen to involve up to 4 levels (Table). In all of the patients the posterior longitudinal and interspinous ligaments were intact and there was no tendency for the disc to herniate into the canal as occurs with a flexion injury. In the 3 patients who expired within 4 weeks, haemorrhage was seen in the articular capsule and extradural space, but there was no massive haematoma compressing the spinal cord. In case 1, there was a large number of areas of small focal necroses in the central part of the spinal cord with general atrophy of the spinal cord. There was a disappearance of parenchyma for $2.5 \mathrm{~cm}$ in the spinal cord of case 2 . In cases 3 and 4 small focal haemorrhages or softening necrosis occurred in the central part associated with diffuse swelling around the focal lesion. Figure 1 shows the post-mortem findings of case 4. Rupture could be seen in two sites of the anterior longitudinal ligament and the macroscopic findings of the osteophyte fracture observed radiologically are indicated with arrows (Fig. 1A). Figure 1B is a longitudinal section of the spine of the same case. Three intervertebral discs were ruptured. The 
Table Patients who had an extension injury of the cervical spine

\begin{tabular}{|c|c|c|c|c|c|c|c|}
\hline $\begin{array}{l}\text { Case } \\
\text { no. }\end{array}$ & Age & Sex & $\begin{array}{c}\text { Cause } \\
\text { of injury }\end{array}$ & $\begin{array}{l}\text { Face or } \\
\text { forehead } \\
\text { injury }\end{array}$ & $\begin{array}{c}\text { Bone injury } \\
\text { on } \mathrm{X} \text {-ray }\end{array}$ & $\begin{array}{c}\text { Grade and level } \\
\text { of neurological } \\
\text { deficit }\end{array}$ & $\begin{array}{l}\text { Survival } \\
\text { time }\end{array}$ \\
\hline 1 & 75 & $\mathbf{M}$ & $\begin{array}{c}\text { Traffic } \\
\text { accident }\end{array}$ & Face & $-\star$ & C4 Incomplete & 21 days \\
\hline 2 & 70 & $\mathbf{M}$ & $\begin{array}{l}\text { Fall from } \\
\text { bicycle }\end{array}$ & & $-\star$ & C5 Complete & 5 months \\
\hline 3 & 73 & $\mathbf{M}$ & Hit by car & Forehead & $-\star$ & C7 Incomplete & 27 days \\
\hline 4 & 64 & $\mathbf{M}$ & $\begin{array}{c}\text { Fall } \\
2 \cdot 5 \mathrm{~m}\end{array}$ & & $\begin{array}{c}+\star \\
\text { Detached } \\
\text { Osteophyte }\end{array}$ & C5 Incomplete & 26 days \\
\hline 5 & 77 & $\mathbf{M}$ & $\begin{array}{l}\text { Fall } \\
4.0 \mathrm{~m}\end{array}$ & & $-\star \star$ & C5 Complete & 9 days \\
\hline 6 & 61 & $\mathbf{M}$ & $\begin{array}{c}\text { Fall } \\
2 \cdot 0 \mathrm{~m}\end{array}$ & Face & $-\star \star$ & C5 Complete & 18 months \\
\hline 7 & 53 & $\mathrm{~F}$ & $\begin{array}{l}\text { Fall on } \\
\text { her face }\end{array}$ & & $-\star \star \star$ & C5 Incomplete & 2 months \\
\hline 8 & 34 & $\mathbf{M}$ & $\begin{array}{l}\text { Thrown into } \\
\text { river } 2.5 \mathrm{~m}\end{array}$ & $\begin{array}{l}\text { Anterior } \\
\text { head }\end{array}$ & - & C5 Complete & 6 days \\
\hline 9 & 39 & $\mathbf{M}$ & $\begin{array}{l}\text { Fall } \\
6.0 \mathrm{~m}\end{array}$ & $\begin{array}{l}\text { Top of } \\
\text { the head }\end{array}$ & $\begin{array}{c}+ \\
\text { Fracture } \\
\text { dislocation }\end{array}$ & C5 Complete & 20 days \\
\hline
\end{tabular}

$\star \quad$ Spondylosis

$\star \star$ Ankylosing hyperostosis

$\star \star \star$ Ossification of posterior longitudinal ligament

spinal cord was swollen and on the longitudinal section of the spine of the same case. Three intervertebral discs were ruptured. The spinal cord was swollen and on the longitudinal section small soft foci could be seen in the central part (Fig. 1B).

\section{Extension injuries to rigid cervical spine}

Cases 5 and 6 had an extension neck injury with ankylosing cervical hyperostosis and complete tetraplegia. Case 6 sustained an abrasion to the face. $\mathrm{X}$-rays of case 5 show osseous fusion of C5-6, C6-7 and a very large osteophyte at C4-5 anterior intervertebral space but no bony injury. Figure 2 shows the autopsy findings of this patient. The external force of the fall was brought to bear on only one area of the rigid cervical vertebra, causing a horizontal rupture of the anterior longitudinal ligament and intervertebral disc between the third and 


\begin{tabular}{|c|c|c|c|c|c|c|}
\hline \multicolumn{3}{|c|}{ Ligament rupture } & \multirow{2}{*}{$\begin{array}{l}\text { Disc } \\
\text { rupture }\end{array}$} & \multirow[b]{2}{*}{$\begin{array}{l}\text { Macroscopic features } \\
\text { of spine }\end{array}$} & \multirow[b]{2}{*}{$\begin{array}{l}\text { Microscopic features } \\
\text { of spinal cord damage }\end{array}$} & \multirow[b]{2}{*}{$\begin{array}{c}\text { Extent of } \\
\text { cord damage }\end{array}$} \\
\hline ALL & PLL & ISL & & & & \\
\hline+ & - & - & $\begin{array}{c}+ \\
3 \text { discs }\end{array}$ & $\begin{array}{l}\text { Haemorrhage in } \mathrm{C} 1-2 \text { facet } \\
\text { joint } \\
\text { Hypermobility in extension }\end{array}$ & $\begin{array}{l}\text { Multiple small focal } \\
\text { necrosis } \\
\text { Atrophy }\end{array}$ & each $0.5 \mathrm{~cm}$ \\
\hline+ & - & - & + & No abnormality, stable & $\begin{array}{l}\text { Disappearance of } \\
\text { parenchyma }\end{array}$ & $2.5 \mathrm{~cm}$ \\
\hline $\begin{array}{c}+ \\
3 \text { places }\end{array}$ & - & - & $\frac{+}{3 \text { discs }}$ & $\begin{array}{l}\text { Haemorrhage in C4-5,5-6, } \\
6-7 \text { facet joint and nerve root } \\
\text { Hypermobility in extension }\end{array}$ & $\begin{array}{l}\text { Oedema with small } \\
\text { focal necrosis }\end{array}$ & $7.0 \mathrm{~cm}$ \\
\hline $\begin{array}{c}+ \\
2 \text { places }\end{array}$ & - & - & $\begin{array}{c}+ \\
3 \text { discs }\end{array}$ & $\begin{array}{l}\text { Marginal crack fracture of } \\
\text { C6 } \\
\text { Hypermobility in extension }\end{array}$ & $\begin{array}{l}\text { Oedema with small } \\
\text { focal necrosis }\end{array}$ & $7.0 \mathrm{~cm}$ \\
\hline+ & - & - & + & $\begin{array}{l}\text { Haemorrhage in C3-4 facet } \\
\text { and extradural space } \\
\text { Excessive extension at } \\
\text { injured site }\end{array}$ & $\begin{array}{l}\text { Small cavity with } \\
\text { haemorrhage } \\
\text { Oedema }\end{array}$ & $0.5 \mathrm{~cm}$ \\
\hline+ & - & - & + & $\begin{array}{l}\text { Ossification of ALL } \\
\text { Spinal canal stenosis } \\
\text { Slight movement at C3-4 }\end{array}$ & $\begin{array}{l}\text { Disappearance of } \\
\text { parenchyma } \\
\text { Atrophy }\end{array}$ & $7 \cdot 0 \mathrm{~cm}$ \\
\hline+ & - & - & $\begin{array}{c}+ \\
2 \text { discs }\end{array}$ & $\begin{array}{l}\text { Ossification of PLL } \\
\text { Spinal canal stenosis } \\
\text { Disc rupture at C4-5,5-6 }\end{array}$ & Small cavity & $0.5 \mathrm{~cm}$ \\
\hline+ & - & - & + & $\begin{array}{l}\text { Massive haemorrhage from } \\
\text { C2 to C5 vertebrae } \\
\text { Rupture of C } 3-4 \text { capsular } \\
\text { ligament } \\
\text { Posterior subluxation } \\
\text { in extension }\end{array}$ & Haemorrhagic necrosis & $3.0 \mathrm{~cm}$ \\
\hline+ & - & + & + & $\begin{array}{l}\text { Massive haemorrhage } \\
\text { Bilateral pedicle fracture } \\
\text { Excessive instability }\end{array}$ & $\begin{array}{l}\text { Haemorrhagic necrosis } \\
\text { Haemorrhage in grey } \\
\text { matter }\end{array}$ & $10 \cdot 5 \mathrm{~cm}$ \\
\hline
\end{tabular}

ALL-Anterior longitudinal ligament

PLL-Posterior longitudinal ligament ISL-Interspinal ligament

fourth cervical vertebrae. By passive retroflexion the anterior stump readily separated and the upper vertebra displaced in a posterior inferior direction. Passive axial compression and extension were applied, but there was no posterior prolapse of the disc. It was assumed that the spinal cord was contused between the posterior inferior margin of the upper vertebra and the neural arch of the lower vertebra. A small cavity with haemorrhage was seen in the central part of the spinal cord, and the white matter was swollen (Fig. 2).

Case 7 was a female patient with ossification of the posterior longitudinal ligament from C2 to C4. She struck her head against a door when she fell and became tetraplagic. The C4-5 and C5-6 discs were ruptured and a small cavity was noted in the central part of the spinal cord. She could move both lower extremities. The neural damage was that seen in patients with a central cervical spinal cord injury. 


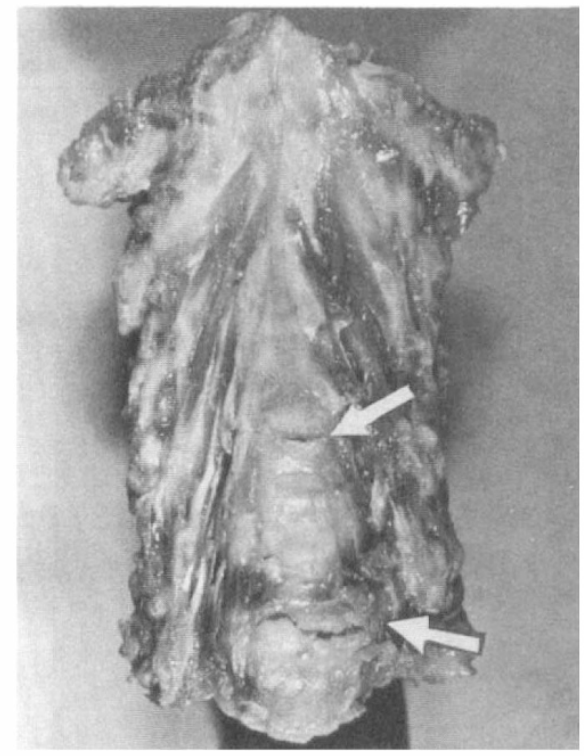

A

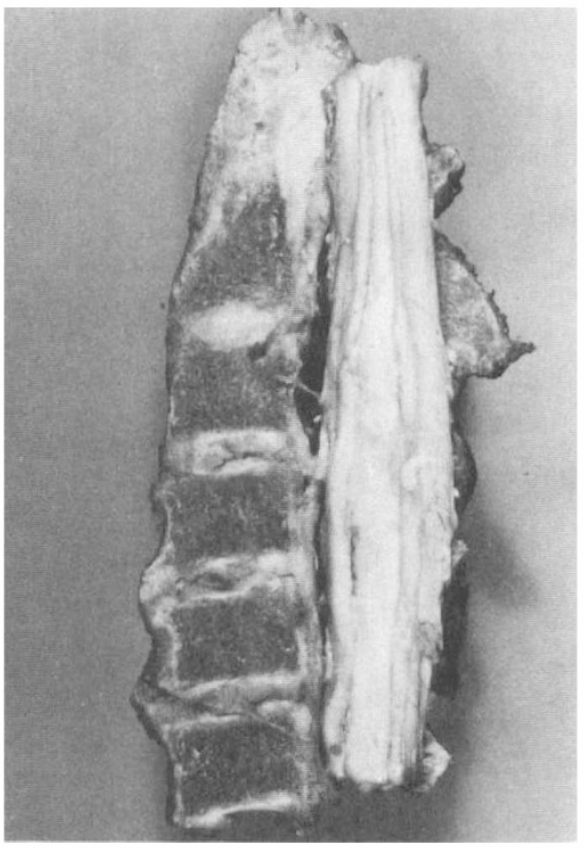

B

Figure 1 Case 4. Extension injury to arthritic spine.

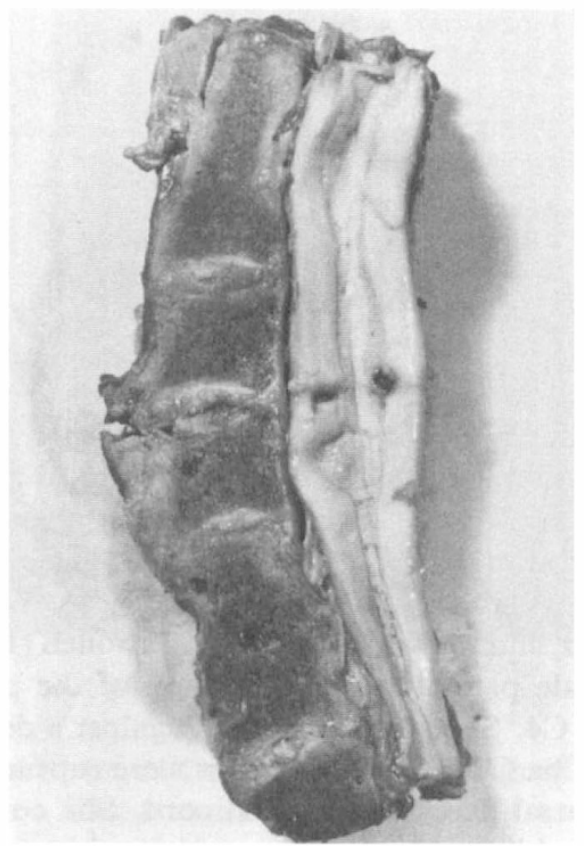

Figure 2 Case 5. Extension injury to rigid spine. 


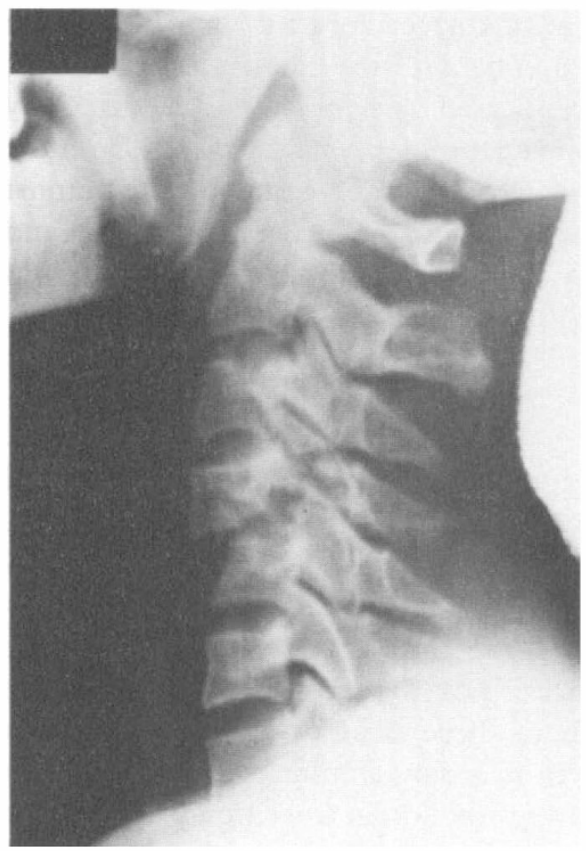

A

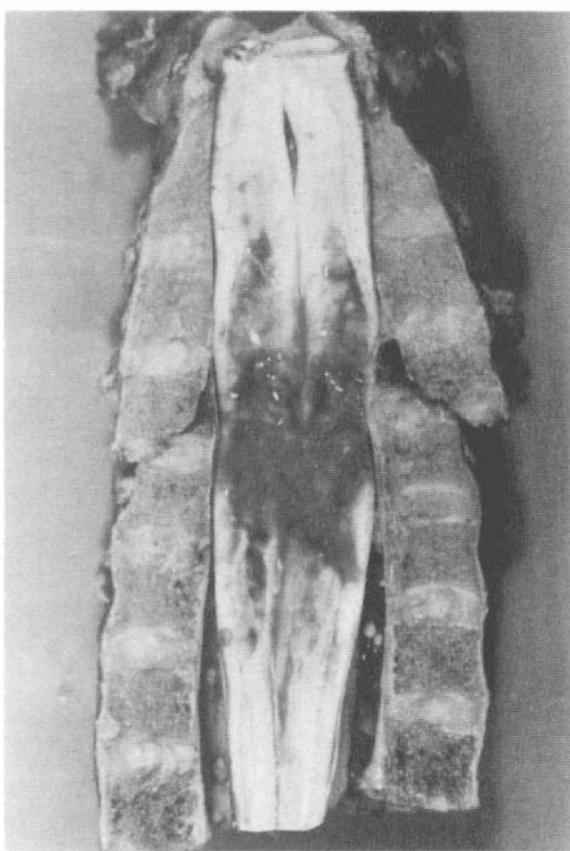

B

Figure 3 Extension fracture dislocation.

\section{Posterior dislocation}

Case 8 was thrown into a river bed injuring the anterior aspect of the head. Complete paralysis developed immediately and the patient died 6 days later. At autopsy, the anterior longitudinal ligament and the C3-4 disc were ruptured, and by passive extension there was. subluxation of the $\mathrm{C} 3$ vertebra with an intact posterior longitudinal ligament which was separated from the posterior superior margin of $\mathrm{C} 4$ vertebra. By anteflexion the subluxation could be easily replaced and the posterior longitudinal ligament became tense and stable. There was little doubt that this occurred during life and thus the X-ray at the initial examination did not reveal any trauma.

The spinal cord showed haemorrhagic necrosis cafe au lait in colour, extending for $3.0 \mathrm{~cm}$.

\section{Extension fracture dislocation}

Patient 9 fell from a height and developed complete paralysis. There were two contusions on the top of the head. Radiologically, the neural arch of C4 was bilaterally fractured at the interarticular portion, and $\mathrm{C} 4$ vertebra was dislocated forwards (Fig. 3A).

At autopsy the spine was transversely severed between C4-5 and the stability was completely lost. The $\mathrm{C} 4$ neural arch had become an isolated fragment like the neural arch in spondylolisthesis and was connected with the C3 and C5 neural arches only by the ligament flavum. A fracture line was observed to run 
obliquely from the central posterior margin of $\mathrm{C} 4$ vertebra through the disc to the anterior superior margin of C5 vertebra. The anterior longitudinal ligament was also ruptured and C4 vertebra was dislocated as if pushed forward. Only the posterior longitudinal ligament escaped rupture and was separated from the posterior surface of $\mathrm{C} 4$. The parenchyma of the three segments had almost completely disappeared by severe haemorrhage and colliquative necrosis and there was haemorrhage in the upper and lower grey matter. The lesion was $10.5 \mathrm{~cm}$ in length.

\section{Management}

Conservative treatment is required for hyperextension injuries of the cervical spine, and surgery is not indicated except for extension fracture dislocation. Most extension injuries are stable because the posterior ligament complex is not ruptured. The patient's neck should be held in a neutral position and hyperextension should be avoided. There is no indication for skeletal traction by skull traction because the intervertebral disc is not displaced backward into the spinal canal. For the extension injury where there is ankylosing hyperostosis and posterior dislocation as in case 7 , there is a danger that the dislocation at the time of injury will be reproduced by strong traction in the extended position. The patient should be nursed in a shell or between sandbags in a neutral position or in a position of slight flexion.

In extension fracture dislocation masqueraded as a flexion injury, the spinal column becomes remarkably unstable due to the fracture of the vertebral body, disc and neural arch and to the rupture of all of the ligaments except for the posterior longitudinal ligament. Partial reduction was achieved by skull traction in case 9 , but the patient expired 20 days later. If the patient had survived, a surgical fixation procedure for the spine may have been necessary.

\section{Discussion}

Hyperextension injury to the arthritic spine of elderly individuals does not show as a bony injury on X-ray study, but the anterior longitudinal ligament rupture with a tear through an intervertebral disc can be observed in all of the cases at autopsy. But it has been found in many of the cases that there are multiple injuries.

According to Taylor (1951), the mechanism of spinal cord injury is that the cord is trapped anteriorly by the osteophytes and posteriorly by the inward bulging of the ligamentum flavum, while Schneider (1958) claims that the cord is compressed or squeezed in several places causing intramedullary haemorrhage and oedema.

A large number of small focal haemorrhages and necroses can be seen in the central portion of the spinal cord, but the subpial white matter was well preserved (Cases 3 and 4 ). In many of the patients there was an incomplete paralysis. As swelling of the spinal cord was evident even 4 weeks following injury (Cases 3 and 4), it can be assumed that more severe oedema had been present 1 to 2 weeks after injury. Bedbrook (1977) stated that early in the pathological process the cord swells rapidly and probably fills the neural canal for a consider- 
able distance of the cord. Extreme gentleness is required at the time of initial management to ensure that no further damage is inflicted to the cord which is already swollen and is therefore without its usual elasticity and movement pattern. The authors agree with their pathological findings.

Most extension injuries of the cervical spine are stable because the posterior ligament complex is not ruptured. These injuries should therefore be treated conservatively. The patients neck should be held in a neutral position without the application of hyperextension.

It is unlikely that a decompression laminectomy will be effective, for according to Rand (1962) it may even be injurious. The reason for this is that the acute compressive force of the bulging ligamentum flavum present during hyperextension is no longer present with the cervical spine in the neutral position. Furthermore operative manipulation may injure the long tracts which are maintained intact subpial in a rim shape, and there is a risk of aggravating incomplete paresis to become complete tetraplegia. In addition, resection of the intact posterior ligament complex and neural arch results in instability of the cervical spine which has an injury to the anterior longitudinal ligament and intervertebral disk at several levels, and will lead to difficulty in nursing the patient.

Guttmann (1966) has reported on traumatic tetraplegia in 4 patients who had ankylosing spondylitis. All had complete motor paralysis with some recovery of sensation in only 1 patient.The authors' 2 cases of ankylosing cervical hyperostosis (Cases 5 and 6 ) also had complete paralysis. Cord damage observed in case 5 is shown in Figure 3B. Disappearance of the parenchyma was observed in the spinal cord of case 6 . It is considered that the external force on the cervical spine which has decreased mobility and elasticity converged at one site to severely crush the spinal cord. In case 7, due to ossification of the posterior longitudinal ligament the anterior-posterior diameter of the spinal canal was decreased to $0 \cdot 7 \mathrm{~cm}$. Due to the pre-existing narrowness of the canal, central spinal cord injury was induced by even a minimal external force, and an intramedullarly small cavity was seen.

Case 8 is a patient who had a recoil injury. This was a 34-year-old male who following a hyperextension injury sustained momentary posterior subluxation of C3 and severe crushing of the spinal cord, but spontaneous reduction occurred. Taylor and Blackwood (1948) have also reported a case of recoil injury of C6-7 in a 34-year-old male. In both cases, the posterior longitudinal ligament was not ruptured, but it was separated from the posterior surface of the inferior vertebra and was dislocated together with the superior vertebra. In a hyperextension injury the anterior longitudinal ligament is invariably ruptured, but no patient had rupture of the posterior longitudinal ligament. The intactness of this ligament is considered to be important for the stability of the cervical spine.

If skull traction is carried out in the extended position, there is a danger that the condition at the time of injury will be reproduced and that the spinal cord will be further damaged, and therefore traction is counterindicated. The patient should be treated with the cervical region in a neutral position or in a slightly flexed position.

In case 9 with a fracture dislocation, an extensive longitudinal cord injury was 
observed. Extreme instability was observed between cervical vertebrae C4-5 and the only soft tissue connecting $\mathrm{C} 4$ and $\mathrm{C} 5$ was the posterior longitudinal ligament, but this was extensively separated from the posterior surface of $\mathrm{C} 4$ and relaxed. In view of these autopsy findings, it is considered that a more severe dislocation was present at the time of injury and the spinal cord was damaged irreversibly by crushing and stretching as well as by a rotational shearing force. Haemorrhage and necrosis were present not only at the main site of injury but also in the segments above and below. These pathological changes are considered to be attributable not only to the physical injuries of the neural tissue due to direct force but also to post-traumatic self-destruction processes.

It is known that necrosis and softening of the site of spinal cord injury develop and irreversible changes are completed within 24 hours after such injury (Goodkin, 1969; Kakulas, 1984).

In view of these pathological findings in the present cases, when complete paralysis develops simultaneously with fracture dislocation and when such a condition persists for 24 hours or more, a surgical operation should not be performed in an attempt to achieve neural recovery (Guttmann, 1949; Bedbrook, 1963; Hardy, 1975).

Essentially, this type of trauma is the most severe spinal injury found amongst extension injuries, and it cannot be cured conservatively and due to continued instability and pain, difficulty is experienced in rehabilitation. We report on a 47-year-old female who after suffering from a compression extension fracture dislocation of C6-7 was unable to assume a sitting position even 1 year after injury because of instability and neck pain, and therefore operative spinal fusion was undertaken. Forsyth has conducted a rigid bone graft and rigid internal fixation such as wiring two vertebrae above the level of injury and two vertebrae below this level securely to the rigid graft. However, the authors after removing the vertebral arch made an $\mathrm{H}$ graft of the iliac bone in the space and wired the upper and lower vertebral arches together. Post-operatively $2 \mathrm{~kg}$ skull traction was continued for 6 weeks to achieve a cure.

\section{References}

BARNES R 1948 Paraplegia in cervical spine injuries. Fournal of Bone and foint Surgery 30B:234244.

BEDBROOK GM 1963 Some patient observations on the pathology of traumatic spinal paralysis. Paraplegia 1:21 5-227.

BEDBROOK GM 1977 Compression, flexion and extension injuries of the cervical spine with tetraplegia. Proceedings of Nineteenth Veterans Administration Spinal Cord Injury Conference. Scottsdale, pp 6-28.

BURK DC 1971 Hyperextension injuries of the spine. Fournal of Bone and foint Surgery 53B:3-12.

FORSYTH HF 1964 Extension injuries of the cervical spine. Fournal of Bone and foint Surgery 46A: $1792-1797$.

GUTTMANN L 1949 Surgical aspects of the treatment of traumatic paraplegia. Fournal of Bone and foint Surgery 31B:399-403.

GuttMAnN L 1966 Traumatic paraplegia and tetraplegia in ankylosing spondilitis. Paraplegia 4:188-203.

Goodkin R, CAMPBell JB 1969 Sequential pathologic changes in spinal cord injury: A preliminary report. Surgical Forum 20:430-432.

HARDY AG, Rossier AB 1975 Spinal Cord Injuries, Georg Thieme Publishers, Stuttgart, pp 53.

Kakulas BA 1984 Pathology of spinal injuries. Central Nervous System Trauma 1:117-129 Mary Ann Liebert Inc., Publishers. 
RAND RW, CRANDALl PH 1962 Central spinal cord syndrome in hyperextension injuries of the cervical spine. Fournal of Bone and foint Surgery 44A:1415-1422.

SCHNEIDER RC, CHERRY G, PANTEK H 1954 The syndrome of acute central cervical cord injury with special reference to the mechanism involved in hyperextension injuries of cervical spine. Fournal of Neurosurgery 11:546-577.

TAYLOR AR, BLACKWOOD W 1948 Paraplegia in hyperextension cervical injuries with normal radiographic appearances. Fournal of Bone and foint Surgery 30B:245-248.

TAYLOR AR 1951 The mechanism of injury to the spinal cord in the neck without damage to the vertebral column. Fournal of Bone and foint Surgery 33B:543-547. 